\title{
Perception of Nursing Faculty Members on the Use of Objective Structured Clinical Examinations (OSCE) To Evaluate Competencies
}

\author{
Dr. Wajed Hatamleh ${ }^{1}$, Dr. Zeinab Abu Sabeeb ${ }^{2}$ \\ ${ }^{I}$ Prince Sultan Military medical City, Center for Health Studies -Department of Nursing, Saudi Arabia \\ ${ }_{2}^{2}$ Prince Sultan Military medical City, Center for Health Studies -Department of Nursing, Saudi Arabia
}

\begin{abstract}
:
Background: Assessment of clinical skills has a central role in nursing education and the selection of suitable methods has been a matter of permanent concern for clinical teachers, course directors and educators. there are no studies in the nursing literature examining the use of the OSCE as a method for evaluating the performance of clinical skills by nurses.The aim of this study was to describe faculty's' perceptions toward the first OSCE implemented at Center for Health Studies, Nursing Department (CHS-ND).

Methodology: A descriptive, Cross sectional study was carried out on the faculties who were deeply involved with the OSCE. Data was collected from 20 faculty members by Self-explanatory questionnaire immediately after students completed the examination.

Results: The overall perceptions of the faculty members were positive toward the exam. About $75 \%$ of the faculties found that OSCE allowed students to display knowledge on nursing related problems nevertheless. Fifty percent of the lecturer admitted that students' stress level impacted their performance on OSCE. While $50 \%$ of the lecturer confirmed that the scenarios felt realistic with the use of actors. Bias is significantly reduced in this method of evaluation as up to $85 \%$ agreed that OSCE is an effective way to test nursing competencies.

Conclusion: OSCE was accepted and perceived positively by nursing faculties as a new method to assess clinical skills. The survey further highlighted for future refinement the strengths and weaknesses associated with development and implementation of an OSCE in the CHS-ND.
\end{abstract}

Keywords: OSCE, Faculty, perception, Clinical evaluation, Nursing Education, Students.

\section{Introduction}

Assessment of clinical skills has a central role in nursing education and the selection of suitable methods has been a matter of permanent concern for clinical teachers, course directors and educators, assessment of clinical competence, requiring educators to make informed decisions that measure students' clinical knowledge and skills accurately, an effective educational system is realized through effective assessment and evaluation methods [1]. Some concern had been expressed by Gillings \& Davies about the unrealistic and the artificial nature of the traditional system of clinical evaluation, learners would pass the examination with high marks - up to $100 \%$, but would not make any difference in the clinical practice with regard to improvement on clinical reasoning skills [2], such clinical assessments have often been challenged by a lack of objectivity. Bondy, reported that, assessment of clinical practice skills in health profession's education poses several challenges in terms of its objectivity and the valuation of clinical competence of students is usually considered subjective and inconsistent, [3]. It is therefore important to utilize trustworthy assessment and evaluation methods in clinical nursing education.

Objective structured clinical examination (OSCE) is one form of objective evaluation method that is gaining more importance and is being adopted by educators of various disciplines especially when the merits of OSCE outweigh the demerits and motivates student learning, it involves use of cognitive skills like critical thinking and problem solving, OSCE also enhances good interaction between the teacher and the student, learners need critical and reflective thinking skills to be evaluated in order to be safe and competent practitioners of the profession $[4,5,6]$.

The OSCE is now established as one of the most valid, reliable and effective tests for the assessment of clinical skills [7], it was introduced by Harden in 1975 and has become a well-established method of assessment in medical education [8] and has been in use in the assessment of medical students for over 20 years then increasingly being used as a method of assessment in nursing and allied health curricula [9,10], also Harden and Caincross reported that, since its inception, the OSCE has been increasingly used to provide formative and summative assessment in various medical disciplines worldwide, including non-clinical disciplines [11]. The OSCE is a form of assessment in which the student demonstrates clinical skills, and underpinning knowledge, usually in simulated conditions [12], OSCE is capable of evaluating the achievement 
of the three domains of educational objectives; cognitive, attitude and psycho- motor. So that students demonstrate their competence in a variety of simulated conditions [13]. OSCE sessions perceived strengths, weaknesses, and challenges in clinical competence, foster self-assessment skills, and provide direction for programme training needs, and it offer a valid mean to evaluate students' clinical performance in a holistic manner, [14, and 15]. In a typical OSCE, examinees rotate through a number of stations staffed by either real or standardized patients, where they are required to perform different clinical tasks. The examinees are observed and their performance is assessed using structured checklists [16]. Whether OSCEs assess clinical safety or role competence is an area of debate, Chabeli suggests the use of varied alternative methods for clinical assessment and evaluation for nursing students because OSCE does not measure the learners' clinical competence holistically [17].

OSCE is practiced worldwide in nursing education, but its practice in developing countries is scarce; the nurse educators from developing countries should be encouraged to utilize this form of evaluation. Although a considerable body of knowledge concerning technical and organizational aspects of OSCE administration is now available; little has been published on the responses of nursing faculty members.

The aim of the study was to obtain feedback from instructors who were involved in the introduction of the first OSCE at CHS-ND in order to refine and standardise the format throughout the curriculum.

Permission to conduct the survey was obtained from the Director of Center and from the Ethics Committee of Nursing Department. In addition, informed consent was obtained from the instructors and they were assured of both anonymity and confidentiality. The instructors also participated voluntarily after being briefed in full about the nature of the study. All instructors confirmed that they understood their right to withdraw from the study at any point.

\section{Material And Methods}

A descriptive, cross-sectional, study design was conducted during the final clinical exam in the 20132014, academic year. The study sample included all instructors who involved in OSCE at CHS-ND. No sampling was done as the total population (20) was included in the study.

The examination committee compiled an OSCE guideline, this guideline include information on conducting the assessment itself and the relevant information on the time allocated for all possible procedures, as such these information guided the students in their preparation for the assessments. In an attempt to give the students a proper experience of the assessment process, a practice review and how the OSCE would operate took place two week before the exam, adequate preparation and familiarization for students were done; particularly with regards to the skills to be reviewed, the nature of the OSCE at each station and the process of the examination, the assessment strategy was discussed with the students and they were encouraged to ask questions and discuss issues around the OSCE. It was clear that the students who had been through a proper practice felt more prepared and ready for the OSCE. All instructors received detailed training on OSCE before the actual exam and assignment for preparing and coordination of the OSCE. The OSCE stations consisted of a series of 12 stations, about 6 minutes for each, in each station candidate was examined on a one-to-one basis with one examiner and either real or simulated patients. To overcome the limited number of a simulator in the skill labs, standardized patients were used in the OSCE, in stations where standardized patients were used, detailed scripts were provided to ensure that the information that they gave was the same to all candidates, including the emotions that the patient should use during the examination.

The questionnaire was designed and filled in by the faculty members who involved in OSCE; $(n=20)$ 11 instructors with Master degree and 9 instructors with Bachelor degree. Participants were asked to answer a structured questionnaire containing close-end questions to obtain instructors' perceptions. The questionnaire was divided into three parts; part one contain two items regarding the case scenario content. Part two consisted of six items OSCE testing questions. Part three had 6 items too regarding the logistics of the OSCE. The results were graded on the Likert scale, graded from 1-3; 3 for agree, 2 for neutral and 1 for disagree. The questionnaire was administered immediately after all students completed the examination. Face validation of the questionnaire was done by experienced faculties. The questionnaire was piloted before actual administration to address any ambiguities. The obtained data were coded, analyzed and tabulated. Basic descriptive statistical analysis of the Likert items was performed in the forum of frequencies and percentage these were enhanced by means of bar-graphs.

\section{Results And Discussion}

The experience of introducing an OSCE at PKND for the first time provided an opportunity to learn about faculty member responses. Reflection on this experience has also raised a number of issues related to general aspects of clinical evaluation and assessment. OSCEs have a central role in providing a formative evaluation of clinical competence and patient management skills plays in different clinical disciplines of health 
education [13]. In Brazil, Troncon proposed that absence of a favorable attitude toward innovative educational programs among students and faculty members may ascribe for the limitations of implementing OSCE for clinical evaluation [18], In this study the overall attitude of the faculty members toward OSCE was positive and this will facilitate the implementation of OSCE in CHS-ND in the future.

The response rate among faculty members in this study was100\% ( $\mathrm{n}=20)$. Faculty members' perceptions of an OSCE are summarized in Table 1. The findings of a positive attitude among the faculty members in CHS-ND were consistent with what was said by Godfrey et al, in retrospective analysis of the longitudinal attainment of underperforming students in OSCE assessments [19].

Table 1: OSCE Questions and Frequency of Responses

\begin{tabular}{|c|c|c|c|}
\hline \multirow[t]{2}{*}{ Survey Items } & \multicolumn{3}{|c|}{ Degree of Response } \\
\hline & Agree \% & Neutral \% & Disagree $\%$ \\
\hline $\begin{array}{l}\text { Nursing problems presented in the cases were appropriate for level } 5 \\
\text { students. }\end{array}$ & 70 & 30 & 0 \\
\hline Checklists developed represented appropriate expectations for level & & & \\
\hline 5students. & 70 & 30 & 0 \\
\hline The OSCE evaluated students' communication skills. & 70 & 20 & 10 \\
\hline $\begin{array}{l}\text { The OSCE allowed students to display knowledge on nursing related } \\
\text { problems. }\end{array}$ & 75 & 25 & 0 \\
\hline $\begin{array}{l}\text { The OSCE measured students' application of clinical skills and } \\
\text { abilities required in nursing. }\end{array}$ & 85 & 15 & 0 \\
\hline Using an OSCE is an effective way to test nursing competencies. & 85 & 15 & 0 \\
\hline An OSCE should be part of clinical standardized testing. & 95 & 5 & 0 \\
\hline $\begin{array}{l}\text { Student had adequate time allotted at each station to complete } \\
\text { required tasks. }\end{array}$ & 70 & 25 & 5 \\
\hline Students' stress level impacted the performance on OSCE. & 50 & 40 & 10 \\
\hline The scenario at each station felt realistic with use of an actor. & 50 & 30 & 20 \\
\hline $\begin{array}{l}\text { As an observer, I felt I could stay focused while observing the same } \\
\text { case repeatedly }\end{array}$ & 30 & 0 & 70 \\
\hline $\begin{array}{l}\text { Nursing problems presented in the cases were } \\
\text { appropriate for level } 5 \text { students. }\end{array}$ & 70 & 30 & 0 \\
\hline $\begin{array}{l}\text { Checklists developed represented appropriate expectations for level } \\
5 \text { students. }\end{array}$ & 70 & 30 & 0 \\
\hline
\end{tabular}

The first item in the questionnaire required the instructors to indicate their perceptions as regards to the appropriateness of problems presented in the OSCE for level 5 students, seventy percent of the faculty members $(\mathrm{n}=14)$ agreed that the problems presented in the OSCE were appropriate, the rest of the faculty members were neutral $(n=6)$. These findings are convenient with [20], who reported that, the OSCE reflected what the students were taught, they were fully aware of the nature of the exam which provided them with more learning opportunities.

Since the faculty members involved in the OSCE were also clinical teachers, it was not surprising that most of them reported a perception of positive influence on the checklist that developed represented expectation for level 5 students. Developing a standard checklist for the examiners that includes all the tasks the student is expected to demonstrate, renders a fair scoring process which enables the faculty members to judge the student's clinical knowledge or performance [21]. In this study seventy percent of the faculty members $(n=14)$ agreed that the checklists developed represented appropriate expectation for level 5 students, the rest of the faculty members were neutral $(n=6)$, this result also matches with what has been written in the literature by G. Johnson [22].

Regarding the efficacy of OSCE as a reliable means of evaluating communication and patient management skills $70 \%$ of the faculty agreed, and only $10 \%$ was disagree. These results were consistent with the modified OSCE carried out in 2009 in Pakistan, inclusion of standard patient as one of the items of the exam was shown to be effective in evaluating different aspects of clinical competence including patient management [23]

Our faculty members acknowledged that OSCE is an effective way to test nursing competencies, $85 \%$ agreed while $15 \%$ only were neutral, a similar result was reported by Duffield and Spencer study reported that their faculty members acknowledge the value of the OSCE and their feedback information may potentially lead to improvements in students learning [24].

In terms of that OSCE should be part of clinical standardized testing the majority of the faculty $(n=19)$ agreed. The results indicate that OSCE renders valuable results in evaluating student's clinical knowledge and performance and were more relevant and accurate than previous examinations and particularly acknowledged the aspects relating to objectivity and standardization. These results are in agreement with $(15,20]$. In Fidment's study, it was reported that, the students value the OSCE as a worthwhile assessment [12]. 
It was necessary to determine whether enough time had been allowed to complete the different procedures. In this study the faculties who reported that the exam time was enough for each station were $70 \%$ $(n=14)$ and only 5\% disagree, meaning that these concerns are not in the line to was highlighted by Abraham et. al, who reported in a quantitative study that more than $50 \%$ of the participants felt that time was a concern during the exam [25]. In addition, Hasan et al, indicated that although time does seem to be a problem with the exam, it should not become an exercise of how fast students can perform the technique, but rather focus on how well they can perform it [26]. Each station has to be completed within the same length of time, and stations are run simultaneously, students starting each station at the same time and being required to stop at the same time and then move on to the next station. However, it is essential that the stations be focused so that it is possible to complete specific tasks within a planned time frame [27].

The use of standardized patients (SP) or actors creates a clinically relevant and consistent setting for the evaluation of students and makes the examination as objective as possible, with the guideline being they can tell the student anything that doesn't change the role they are playing and they are consistent with each student. SPs and OSCEs have been used worldwide to assess the clinical skills and competencies of students and professionals in medicine and nursing [28, 29], $\mathrm{n}$ this study those who agreed that prompts given by actors during the OSCE allowed students to compensate for missed tasks are $45 \%(\mathrm{n}=9)$, those who disagree are $15 \%$ $(n=3)$ and those who were neutral were $40 \%(n=8)$.

Regarding students' stress level impacted their performance on OSCE $50 \%(n=10)$ agreed, and only $10 \%$ disagreed, these findings are congruent with the published literature concerning stress and anxiety in students caused by an impending OSCE [30], Schoonheim, et al. reported that dental students ranked an OSCE as significantly more stressful than a written assignment [30]. Similarly, in a study by Byrne and Smyth, preregistration nursing students felt so stressed that it had a negative impact on their performance in an OSCE assessment [31]. However, Byrne and Smyth concluded that students already exposed to an OSCE described feeling less anxious and better prepared for their subsequent clinical placements. This study found similar experiences among the students interviewed. The OSCE had caused feelings of anxiety, yet students felt that the assessment was ultimately beneficial to them. On the other hand, it is conceivable that student stress could be related to fears concerning possible failure, notwithstanding the fact that the observed rates of student failure were similar to those expected for the course. Student stress could also originate from cultural factors, since students tend to perceive assessment procedures and tests as something aiming only at "rewarding a few students and punishing others. Therefore, the introduction of a new examination may have been seen as a rather threatening experience.

Standardized patients have proven to be effective educational tools and have been used extensively in the education of physicians. In fact, approximately $95 \%$ of medical schools in the United States currently use standardized patients and $85 \%$ use them as a component of student assessment Mavis, B. et al. and Major, remarked that it was a challenge to replicate the complexities of clinical practice within a simulated environment $[33,34]$. This again highlights the challenges of using simulation effectively to enhance the learning experience. As Downing and Haladyna, commented, OSCEs are simulations of the real world [35], in this study those who agreed that the scenario at each station felt realistic with the use of an actor were $50 \%(\mathrm{n}=10)$, those who disagreed were $20 \%(n=4)$ and the neutral were $30 \%(n=6)$.

Numerous studies have documented the fact examination bias is significantly reduced in a welldesigned OSCE [20,23] However, some researchers believe that OSCEs are vulnerable to systematic biases due to examiner fatigue, incorporating frequent rest periods for the examiners and involving multiple examiners to evaluate the examinee's performance based on a standard checklist could reduce the possibility of such errors $[36,37]$. In this study, the majority of the faculty members $(70 \%)$ felt that they could stay focused while observing the same case repeatedly.

All faculty members agreed that the OSCE was more relevant and accurate than previous examinations and particularly acknowledged the aspects relating to objectivity and standardization. It was also mentioned by all faculty members that the OSCE had probably been very useful in showing students what skills are important. Other studies reported by Fields et al. have further confirmed the success of OSCE among other assessment methods [38].

The OSCE results were also seen as helpful for this group of clinical tutors in relation to teaching more uniformly. Moreover, the OSCE was perceived as highly effective in revealing a detailed picture of both student performance and course efficacy.

\section{Conclusion}

Overall, OSCE was perceived very positively and welcomed by the faculty members, OSCEs can be used most effectively in nursing undergraduate curricula to assess safe practice in terms of performance of psychomotor skills, this type of exam provided true measurement of clinical skill competencies; therefore OSCE 
should be adopted as a strategy for examining clinical skills for students in all levels. Certain negative perceptions such as stress and difficulty were highlighted, which could be managed with better orientation and preparation of students, including training through mock examination and provision of constructive feedback on their performance. Standardized patients should be increased in number so as to decrease the number of students per patient.

Faculty members had agreed that keeping this model of clinical skills assessment would be worthwhile. Indeed, OSCEs are regarded as a highly valid and reliable method for the assessment of clinical skills. Future research efforts should include qualitative studies to investigate the reasons for negative perceptions such as stress.

\section{Acknowledgements}

The authors acknowledge the contribution and assistance provided by all the instructor and students who participated in success of this first experience of OSCE in CHS-ND.

\section{References}

[1]. Gravett, S. Assessment and Evaluation Methods - OBE. Unpublished paper presented at Forum for University Departments of Nursing in South Africa (FUNDISA AGM) 26-27 May GILLINGS, B \& DAVIES, C. 1998: Evaluating Student Performance. Nursing Times Learning Curve, 2(8), 2000, October, 8-15.

[2]. GillIngs, B \& Davies, C 1998: Evaluating Student Performance. Nursing Times Learning Curve 2(8) October 7: 8-15.

[3]. Bondy, K. Criterion-referenced definitions for rating scales in clinical evaluation. Journal Nursing Education, $22(9)$, $1983,376-82$.

[4]. Jenkins, H. Improving clinical decision-making in nursing. Journal of Nursing Education. 24, 1985, 242 - 243

[5]. MALEK, C. A model for teaching critical thinking. Nurse Educator, 11(6), 1986, 20-23.

[6]. Melllish, J. BRINK, H. and PATON, F. 1998: Teaching and learning the practice of nursing. Johannesburg: Heinemann.

[7]. Howley L. Performance assessment in medical education: where we've been and where we're going. Eval Health Prof, 27(3), 2004, 285-303.

[8]. Ward, H. and Barratt, J. Assessment of nurse practitioner advanced clinical practice skills: using the objective structured clinical examination (OSCE): Helen Ward and Julian Barratt examine how OSCEs can be developed to ensure a robust assessment of clinical competence. Primary Health Care 15(10), 2005, 37-41.

[9]. Bartfay, W. J. Rombough, R. Howse, E., and LeBlanc, R. The OSCE approach in nursing education: Objective structured clinical examinations can be effective vehicles for nursing education and practice by promoting the mastery of clinical skills and decisionmaking in controlled and safe learning environments. The Canadian Nurse 100(3), 2004, 18-25.

[10]. Wessel, J., Williams, R., Finch, E. \& Gemus, M. Reliability and Validity of an Objective Structured Clinical Examination for Physical Therapy Students. Journal of Allied Health 32(4), 2003, 266.

[11]. Harden R. and Caincross, R. The assessment of practical skills: the objective structured practical examination (OSPE). Stud High Educ, 51, 1980, 187-96.

[12]. Fidment, S. The Objective Structured Clinical Exam (OSCE): A Qualitative Study exploring the Healthcare Student's Experience. Student Engagement and Experience Journal, 1 (1), 2012, 1-11.

[13]. Watson, R. Stimpson, A. Topping, A. Porock, D. Clinical competence assessment in nursing: A systematic review of the literatu re. Journal of Advanced Nursing. 39 (5), 2002, 421-431.

[14]. Rentschler, D.J., Eaton, J., Cappiello, et al., (2007). Evaluation of undergraduates' students using objective structured clinical evaluation. Research Briefs, 46 (3): 135-39.

[15]. Pierre, R.B., Wierenga, A. and Barton, M. et al. Student self-assessment in a pediatric objective structured clinical examination. West Indian med. J. 54 (2), (2005, 144-8

[16]. Van der Vleuten CPM. and Swanson D. Assessment of clinical skills with standardized patients: State of the art. Teach Learn Med.1 (2), 1990, 58-76.

[17]. Chabeli, M.M. Nurse educators' perceptions of OSCE as a clinical evaluation method. Objective Structured Clinical Examination. Curationis. South African Journal of Nursing. 24(1), 2001, 84-92.

[18]. Troncon, L.E. Clinical skills assessment: limitations to the introduction of an "OSCE" (Objective Structured Clinical Examination) in a traditional Brazilian medical school. Sao Paulo Medical Journal, 122(1), 2004, 12-17.

[19]. Godfrey Pell, Richard Fuller, Matthew Homer, and Trudie Roberts. How to measure the quality of the OSCE: A review of metric s. Electronic journal of Medical Teacher, 3(10), 2010, 802-811.

[20]. El-Nemer, A. and Kandeel, N.. Using OSCE as an Assessment Tool for Clinical Skills: Nursing Students' Feedback. Australian Journal of Basic and Applied Sciences, 3(3), 2009, 2465-72.

[21]. Doig C.J., P.H. Harasym, GH. Fick and J.S. Baumber. The effect of examiner background, station organization and time of exam on OSCE scores assessing undergraduate medical students physical examination skills. Acad. Med, 75, 2000, 96-98.

[22]. G Johnson, K Reynard. Assessment of an objective structured clinical examination (OSCE) for undergraduate students in accident and emergency medicine. Electronic journal of Accident Emergency Medicine, 10, 2010.

[23]. Igbal, M., B. Khizar and Z Zaidi. Revising an objective structured clinical examination in a resource limited Pakistani Medical School. Edu. Health, 22, 2009, 209-209.

[24]. Duffield KE, Spencer JA. A survey of medical students' views about the purposes and fairness of assessment. Med Educ, 36(9) ,2002, 879-86.

[25]. Abraham R, Raghavendra R, Surekha K, and Asha K. A trial of the objective structured practical examination in physiology at Melaka Manipal Medical College, India. Adv Physiol Educ, 33(1), 2009, 21-23.

[26]. Hassan, F.M.; Al-Kubaisi,A.A., Talib,A.H., Taylor, W. D. and Abdulah, D. S. Phytoplankton primary production in southern Iraqi marshes after restoration. Baghdad Science Journal, 8 (1) ,2011, 519-527.

[27]. Alinier, G. Nursing students'and lecturers'perspectives of objective structured clinical examination incorporating simulation. Nurse Education Today, 23(6), 2003, 419-426.

[28]. Whelan, P. and Jarrett, P. Meerten, M. MTAS fiasco: lessons for psychiatry. Psychiatric Bulletin, 31, 2007, $425-427$. 
[29]. Andersen, P. O., M. K. Jensen, et al. (2010). "Development of a formative assessment tool for measurement of performance in multi-professional resuscitation teams." Resuscitation 81(6): 703-711.

[30]. Brosnan, M. Evans, W. Brosnan, E. and Brown, G. Implementing objective structured clinical skills evaluation (OSCE) in nurse registration programmes in a centre in Ireland: A utilisation focused evaluation. Nurse Education Today, 26, 2005, 115-122.

[31]. Schoonheim-Klein, M. Muijtjens, A. Habets, L. Manogue, M. Van der Vleuten,. C. Van der Velden, U. Who will pass the dental OSCE? Comparison of the Angoff and the borderline regression standard setting methods. EUR J DENT EDUC, 13 (3), $2009,162-$ 171.

[32]. Byrne, E. and Smyth, S. Lecturers' experiences and perspectives of using an objective structured clinical examination. Nurse Education in Practice, 8, 2008, 283-289.

[33]. Mavis, B. Ogle, K. Lovell, K. \& Madden, L. (2002). Medical students as standardized patients to assess interviewing skills for pain evaluation. Medical Education, 36, 135-140.

[34]. Major, D., Seven years on the bandwagon: the progress of an objective structured clinical evaluation programme. Nurse Education Today (2005) 25, 442-454.

[35]. Downing MS, Haladyna TM (2004).Validity threats: overcoming interference with proposed interpretations of assessment data. Med. Educ. 38(3):327-33

[36]. Humphris G.M. \& Kaney S. (2001). Examiner fatigue in communication skills objective structured clinical examinations. Med. Educ., 35:444-449.

[37]. McLaughlin K., M. Ainslie, S. Coderre, B. Wright AND c. VIOLATE, 2009: The effect of differential rater function over time (DRIFT) on objective structured clinical examination ratings. Med Educ. , 43: 989- 992.

[38]. Fields, H.W., M.L. Rowland, K.W.L. Viged and S.S Hujacd, 2007. Objective Structured Clinical Examination use in advanced orthodontic dental education. Am. J. Orthod Dent facial Orthop., 131: $656-663$. 